\title{
Erratum
}

\section{Stability of Explicit Time Discretizations for Solving Initial Value Problems}

R. Jeltsch and O. Nevanlinna

Numerische Mathematik 37, 61-91 (1981)

The equations on page 88, lines 6 and 7 should read as follows:

Line $6 \quad \beta_{1}\left(\beta_{0}+\beta_{1}\right)=\left(\begin{array}{l}m \\ 2\end{array}\right) \frac{1}{m^{2}}$

Line $7 \quad \beta_{1}^{2}\left(\beta_{0}+\beta_{1}\right)=\left(\begin{array}{c}m \\ 3\end{array}\right) \frac{1}{m^{3}}$. 